\title{
VARIANTES DE AUTOR EN \\ LA POESÍA DE JON JUARISTI
}

\author{
AUTHOR VARIANTS IN THE \\ POETRY OF JON JUARISTI
}

\author{
Rodrigo Olay Valdés \\ Universidad de Oviedo
}

RESUMEN: En el presente trabajo nos proponemos sistematizar todas las variantes de autor introducidas por Jon Juaristi en la edición en prensa de sus poesías reunidas, titulada Derrotero. Antes de ello, examinamos los distintos ejemplos de reescritura de catorce poemas de Juaristi desde su inicial publicación en revista hasta que, con las oportunas modificaciones, pasaron a formar parte de alguno de sus libros. En concreto, se analizan los cambios introducidos por el poeta en dos poemas de Arte de marear, dos de Los paisajes domésticos, dos de Tiempo desapacible, tres de Prosas (en verso) y cinco de Renta antigua. Tanto las variantes insertas en estos textos como en la nueva edición de la poesía reunida del poeta nos permiten concluir que Jon Juaristi solo modifica, en la inmensa mayoría de los casos, cuestiones de detalle con objeto de mejorar el cómputo silábico, hacer más preciso el sentido de algún pasaje, allanar alguna referencia cultural levemente remota o suavizar un esguince conceptista de interpretación costosa.

Palabras clave: Jon Juaristi; crítica textual; variantes de autor; métrica.

ABSTRACT: In the present work we propose to systematize all the author's variants introduced by Jon Juaristi in the new edition of his collected poems, entitled Derrotero. Before doing so, we examined the different examples of the rewriting of fourteen poems by Juaristi from their initial publication in a magazine until becoming part of one of his books. Specifically, the changes introduced by the poet in fourteen poems are analysed: two of Arte de marear, two of Los paisajes domésticos, two of Tiempo desapacible, three of Prosas (en verso) and five of Renta antigua. Both the variants inserted in these texts and in the new edition of his collected poetry allow us to conclude that Jon Juaristi only modifies, in most cases, questions of detail in order to improve syllabic computation, make sense more precise in some passage, to smooth over some slightly remote cultural reference, or to smooth out a conceptual sprain of difficult interpretation.

KEY WORDS: Jon Juaristi; textual criticism; author's variants; metrics. 
Hace ahora aproximadamente un año, a principios del confinamiento, Jon Juaristi me envió por correo electrónico un documento Word con su poesía completa, que inicialmente iba a titularse Imán y derrotero. El rótulo procede del lema que, en referencia a Juan Sebastián Elcano, el joven Shanti Andía memorizó por mandato de su tía en la inmortal novela de Baroja: «Por tierra y por mar profundo, / con imán y derrotero, / un vascongado, el primero, / dio la vuelta a todo el mundo» (Baroja, 1963:27), bien entendido que imán vale por 'brújula' y derrotero por 'mapa de ruta marina'. A última hora, el poeta prefirió simplificar el encabezamiento y dejarlo en Derrotero, lo que, difuminando la referencia cultural, acaso un tanto recóndita, acierta a darle al sintético y contundente rótulo adoptado el doble sentido de 'camino','rumbo' y, especialmente, por similitud fonética, de 'derrota'. Abelardo Linares lo publicará en Renacimiento de manera inminente - el libro lleva ya meses entregado (Juaristi, en prensa) - e incluso es posible que aparezca antes de que lo hagan estas páginas.

Lo más novedoso y llamativo de este aún inédito Derrotero son - por encima de los treinta poemas inéditos que incluye, escritos a lo largo de los últimos años y reunidos en la sección final de Restos de fin de temporada (2012-2021) — las correcciones y variaciones insertas por el poeta en sus poemas ya publicados. De hecho, la sistematización de todas esas nuevas variantes de autor - esto es, de correcciones en la obra propia (Lluch-Prats, 2009; Tanganelli, 2014)— será el colofón de este trabajo, que se cerrará con un aparato de variantes que, fruto de los cotejos realizados, registre todos los cambios operados en los textos clásicos del poeta.

Conviene comenzar por recordar que el bilbaíno coleccionó sus versos por vez primera hace más de un cuarto de siglo. Entonces, «Andrés Trapiello me ofreció publicar en La Veleta [...] mi poesía

1 Para más detalles al respecto, véase Juaristi (2019): «Como es sabido, Elcano pudo ostentar desde entonces en su blasón la leyenda latina Primus circumdedisti me ('me circundaste el primero, o me diste la vuelta el primero'). Sobre este motivo se escribieron posteriormente unos versos que Baroja atribuía a un tal Concha que los habría hecho imprimir al frente de un Arte de Navegar por él compuesto y del que no encuentro otra noticia. Los versos en cuestión, según don Pío, rezaban así: «Por tierra y por mar profundo, / con imán y derrotero, / un vascongado, el primero, / dio la vuelta a todo el mundo». Se los hacía aprender de memoria al futuro e intrépido capitán Shanti Andía su tía Úrsula de Aguirre, durante la infancia del protagonista de la gran novela barojiana», etc. Véanse también las observaciones al respecto del poeta en su opúsculo barojiano Los pequeños mundos (Juaristi, 2018a: 64). 
reunida. Esta apareció en 1994 bajo un título que quería ser despedida [...]: Mediodía (1985-1993)» (Juaristi, 2006: 382). Seis años después, Visor imprimía aumentada su Poesía reunida (1985-1999) (Juaristi, 2000). Hoy por hoy, como hemos advertido, el bilbaíno tiene en prensa el ya citado Derrotero (Poesía reunida 1969-2021), en el que incorpora, como liminar, dos poemas de juventud, precisamente de $1969^{2}$, y, como colofón, la ya mencionada treintena de poemas inéditos —anticipados algunos en Anáfora (n. ${ }^{\text {os }} 15,17,19,21,23$ ) - escritos desde la publicación de su último libro en 2012, lo que hace destacar este compendio sobre los precedentes, en los que apenas se incluían ocho poemas inéditos (1994: 169-181) y uno solo (2000: 193-194), respectivamente.

Hay que decir, ante todo, que en Juaristi no son insólitas las reescrituras que aquí atenderemos, pero sí inhabituales. De hecho, el poeta bilbaíno nunca había modificado el texto de sus poemas cuando los hizo pasar desde sus libros exentos a los compendios de 1994 y 2000. Los cambios se concentraban hasta ahora en su caso un salto más atrás: esto es, en el trasvase de los poemas adelantados en revistas y luego incluidos en sus libros. Ahí sí que nos cumple advertir diferentes ejemplos de reescritura, como de inmediato pasaremos a ejemplificar con una serie de muestras significativas.

Sea como fuere, hay otro ejercicio no infrecuente en Juaristi que también hemos de considerar y que se concentra en los primeros compases de su trayectoria; me refiero a la autotraducción de un original vascuence a un nuevo poema castellano, tal como venimos de notar en nuestra nota 2. Es más, muchos de los poemas que conforman su primer libro, Diario del poeta recién cansado, consisten en realidad en traducciones castellanas de originales euskéricos. Por ejemplo, en el monográfico 3 de la revista Los Cuadernos del Norte, titulado El estado de las poesías (1986) y en que se recogen las actas de los Encuentros

Se trata de dos composiciones originalmente euskéricas publicadas en traducción castellana por Juaristi en 1969 en la revista Poesía Española (Juaristi, 1969: 26-27). Acerca de ambos textos ha contado el poeta, con la causticidad que lo caracteriza: «Me planté allí [en casa deVicente Aleixandre] en una tertulia, el año sesenta y ocho, recomendado por [Blas de] Otero y por [Gabriel] Aresti. Con unos cuantos poemas en el bolsillo. José Luis Cano me propuso publicar alguno de ellos en Ínsula. Se los quedó, pero luego aparecieron en Poesía Española. No sé por qué. Eran dos poemas muy raros, muy simbolistas. Hicieron tales elogios de los mismos (Aleixandre, Cano y creo recordar que también [Rafael] Morales) que sospeché enseguida que debían de ser muy malos, y pasé varios años sin escribir poesía» (Juaristi en Olay Valdés, 2017: 28). 
deVerines del año anterior, aparecen precisamente cinco poemas vascuences de Juaristi (1986:143-144) que en el momento del encuentro eran inéditos, pero que cuando aparece la revista ya habían sido publicados en castellano en Diario del poeta... Se trata, en detalle, de «Poética», de tres de los eliotianos «Trenos de Vinogrado» — en particular, los titulados «I», «III» $\mathrm{y}$ «VIII» según la numeración definitiva (Juaristi, 2000: 14-17) — y de «Sermón de la atalaya de Lequeitio». Los originales éuskaros se acompañan de una pequeña indicación parentética, «Versión del propio autor» (Juaristi, 1986: 143), que parece ratificar la preeminencia o anterioridad de los textos en vasco - lo que confirma que Juaristi aparezca en ese monográfico junto con otros poetas euskéricos, como Atxaga o Urkizu, cuyos poemas se ofrecen en su lengua original, acompañados de traducciones castellanas, en su caso mayormente instrumentales-. Este sustrato vasco de la poesía de Juaristi, relevante hasta el punto de que, como vemos, algunos de sus poemas castellanos en realidad son autotraducciones de originales vascuences desconocidos, debe hacerse extensivo a otras muestras de su primer libro y ejemplifica a la perfección que la reescritura a la que Juaristi ha sometido sus textos no consiste solo en afinar algunas de sus lecturas dentro de una sola lengua.

No obstante, dejemos a un lado esta peculiaridad y volvamos a nuestro planteamiento inicial. Como observábamos, Juaristi no ha variado hasta la fecha sus poemas al configurar sus dos primeras compilaciones poéticas (Juaristi, 1994 y 2000) —dejando al margen pequeños cambios en ciertas dedicatorias, como en el poema «Ser antes», dirigido "A Igone» en Tiempo desapacible (1996a:36) y sin dedicataria en la Poesía reunida (2000: 78) - , pero sí ha solido hacerlo al reunir en sus libros exentos poemas previamente adelantados en revistas; o, dicho de otro modo, Juaristi ha entendido la publicación de poemas en revistas como una prueba todavía modificable que adquiere carácter definitivo al pasar tales poemas a configurar uno de sus libros. Solo en sus obras completas en prensa, decimos, podemos advertir por vez primera cambios con respecto a los poemas anteriormente publicados en libro. A este último aspecto dedicaremos los últimos compases de nuestro trabajo; a renglón seguido nos centraremos en identificar los distintos tipos de cambios que Juaristi ha introducido en sus poemas anticipados en revista hasta el momento de confeccionar sus libros.

En primer lugar, hemos de indicar que en algunos casos no hemos encontrado ninguna variante entre el texto dado a conocer en revista y la versión después publicada en libro; por ejemplo, entre «Il 
compagno» (Juaristi, 1995: 41-42; 1996: 23-24). En segundo lugar, que no trabajamos con un corpus exhaustivo, que sería difícil de reunir y que excede las posibilidades y objetivos de este artículo. Hemos hecho una serie de calas significativas revisando aquellas revistas de poesía en las que Juaristi colabora o ha colaborado con mayor asiduidad: Renacimiento, Hélice o Clarín, sin perder de vista otros poemas aparecidos puntualmente en publicaciones como Revista de Occidente o Calle Mayor. En concreto, trabajamos con un total de catorce poemas: dos que después pasaron a formar parte de Arte de marear ( Mox nox» $\mathrm{y}$ «Palinodia», inicialmente titulados «Baladas del fin de la juventud $\mathrm{I} » \mathrm{y}$ «II»), dos de Los paisajes domésticos («Deber de podredumbre» $\mathrm{e}$ «Intento formular mi experiencia de la poesía civil»), otros dos de Tiempo desapacible («Comentario de texto» $\mathrm{y}$ «Dos ciudades»), tres de Prosas (en verso) («Maestu», «Dama de Elche» y «Veinticinco pluvioso») y cinco de su último libro hasta la fecha, Renta antigua («Restaurante chino», «Ligero de equipaje», «Afasia», «Tomás Bilbao, ministro de la Segunda República española, desembarca en Veracruz, el 22 de mayo de 1942» y "Contra John Ford»).

Y bien, hemos de apresurarnos a aclarar que la mayor parte de los cambios suelen consistir en correcciones de detalle, en la sustitución de palabras por otras equivalentes o muy similares, guiado el poeta por diversos motivos concretos que atañen a las características de cada texto. Podemos poner diversos ejemplos de esto, porque, como decimos, rara vez los poemas de Juaristi experimentan una transformación mayor que la descrita en el paso de revista a libro.

Procediendo por orden cronológico, podemos ver, en primer lugar, que la revista logroñesa Calle Mayor adelantó en 1987 los dos poemas que al año siguiente abrirían Arte de marear, a saber: «Palinodia» $\mathrm{y}$ «Mox nox». Originalmente, llevaban por título conjunto el de «Baladas del fin de la juventud», sin otro rótulo particular que «I» $\mathrm{y}$ «II». En su paso al libro, Juaristi decidió titularlos separadamente y también se resolvió a invertir su orden —abre Arte de marear el poema "Palinodia», que originalmente era la «Balada» «II»; al que sigue «Mox nox», la «Balada» «»—; con todo, la continuidad entre ambos textos nunca llegó a ser disuelta del todo, pues, al fin y a la postre, se trata de poemas que siempre han aparecido juntos - no en vano, uno habla de la condición del yo poético como padre; y el otro, del paso del tiempo y del acercamiento físico del locutor poético a su propio padre, fruto del envejecimiento-. 
BALADAS DEL FIN DE LA JUVENTUD

I

«Turn the key and bolt the door, sweet is death forevermore». Ralph Waldo Emerson

$[\cdots]$

Solo tornan a la memoria remordimientos lacerantes, $y$ ecos de pasos que se pierden hacia ninguna parte.

Y detrás de la puerta son las risas de las estudiantes como el piafar de potros uncidos al carro aquel que oyera Marvell.

Fuera oscurece. Cierro el libro. Veo después, al levantarme, en el cristal sombrío reflejado el rostro de mi padre.

(Juaristi, 1987: 89).
MOX NOX

«But at my back I always hear time's winged chariot hurrying near". Andrew Marvell

"Turn the key and bolt the door, sweet is death forevermore». Ralph Waldo Emerson

\section{$[\ldots]$}

Solo tornan a la memoria remordimientos lacerantes, ecos de malos pasos dados hacia ninguna parte.

Y detrás de la puerta son las risas de las estudiantes como el piafar de yeguas uncidas al carro aquel que oyera Marvell.

Fuera oscurece. Cierro el libro. Veo después, al levantarme, en el cristal sombrío reflejado un rostro. El rostro de mi padre.

(Juaristi, 1988: 16-17).

En el primero de estos poemas — siguiendo la disposición de Calle Mayor - los cambios se concentran al principio y al final.Ya hemos comentado el cambio de título, que de «I» pasa a la locución latina que vale por 'noche cercana', pero también hemos de mencionar en su encabezado la incorporación de una nueva cita, en este caso del poeta inglés Andrew Marvell, lo que resulta plenamente lógico dado que este autor satírico es explícitamente citado en la penúltima estrofa de la composición. Es ahí, en el v. 24, donde se alude al «carro aquel que oyera Marvell», precisamente mencionado en la nueva cita. Se trata, en efecto, del "winged chariot», el 'alado carro' del tiempo que el británico evoca en su poema «A su recatada amante»: «Pero a mi espalda no dejo de oír / cómo va persiguiéndome el alado carro del tiempo» (Marvell, 2006: 102), según la traducción de Carlos Pujol. Parece un ejemplo de cortesía con el lector añadir esta cita para así aclarar una alusión relativamente oscura, pues de Andrew Marvell (1621-1678), por más que esté traducido al castellano, no puede decirse que sea un poeta muy conocido en España.

Los otros tres cambios, circunscritos a los vv. 27, 31 y 36 , suponen pequeñas modificaciones que ayudan a perfilar algo el sentido del 
poema. Así, los más inconcretos "pasos que se pierden» se corrigen y clarifican en «malos pasos dados» (v. 27); los «potros» se tornan «yeguas», buscando una mayor precisión léxica; y, por fin, el más abrupto verso final de la versión primigenia, de siete y no nueve sílabas como el resto del romance, se uniformiza en eneasílabo buscando un efecto sorpresivo similar ya no mediante el cambio de metro por otro más breve, sino a través de la repetición de la palabra «rostro».

\section{BALADAS DEL FIN DE LA JUVENTUD}

II

PALINODIA

\section{A Martín}

No te roce siquiera la nostalgia si, al hojear el álbum de guardas desvaídas, un colegial de floja cazadora, cuyos ojos presagian el alcohol de los años inhóspitos que estaban al acecho, te mira desde el fondo del retrato como si nunca hubiera roto un plato.

Te engañarás si adviertes sutileza de espíritu en su expresión. No había nada de eso. Yo lo conocí bien. Poseía tan solo una rara panoplia de estrategias mezquinas para salvar el tipo. Suponía el cuitado que la de la inocencia

no es tan mala apariencia.

Pero la prematura madurez pesa pronto y además no amortiza el esfuerzo invertido. Los réditos que rinde son paja dada al viento. Vas listo si pretendes sacarle otro provecho que la fama de santo (lo que no es para tanto). Escapó como pudo, abriendo una tronera, hacia donde sentía bullir la primavera.

Y, para su desgracia, se dio cuenta a deshora que los aromas fuertes le sentaban fatal, sobre todo el de ciertas florecillas del mal. Anduvo dando tumbos de jardín en jardín, reprimiendo la náusea, mas sucedió que, al fin, no tuvo más remedio, dada su edad ya crítica, que meterse en política.

Pero tampoco en esto le lució mucho el pelo, pues arreglar el mundo no está nunca al alcance de quien tiene su casa en permanente ruina. Pure perte, sa vie. No sacaría ni un rescoldo de amor de aquellos tiempos de ilusiones y dulce desvarío.

No te roce siquiera la piedad, hijo mío.

\section{PALINODIA}

\section{A Martín}

No te roce siquiera la piedad si, al hojear el álbum de guardas desvaídas, un colegial de floja cazadora, cuyos ojos presagian el alcohol de los años inhóspitos que estaban al acecho, te mira desde el fondo del retrato como si nunca hubiera roto un plato.

Te engañarás si tomas por finura de espíritu tal expresión, pues nada había de eso. Yo lo conocí bien. Poseía tan solo una rara panoplia de estrategias mezquinas para salvar el tipo. Pensaba el muy estúpido que la de la inocencia no era mala apariencia.

Pero la prematura rigidez pesa pronto y además no amortiza el esfuerzo invertido. Los réditos que rinde son paja dada al viento. Vas listo si pretendes sacarle otro provecho que la fama de santo (lo que no es para tanto). Escapó como pudo, abriendo una tronera, hacia donde sentía bullir la primavera.

Y, para su desgracia, se dio cuenta a deshora de que algunos aromas le sentaban fatal (sobre todo el de ciertas florecillas del mal). Anduvo dando tumbos de jardín en jardín, reprimiendo la náusea, hasta que un día, al fin, no tuvo más remedio, dada su edad ya crítica, que meterse en política.

Pero tampoco en esta le lució mucho el pelo, pues arreglar el mundo no es tarea al alcance de quien tiene su casa en permanente ruina. Pure perte, sa vie. No guardaría ni un rescoldo de amor de aquellos tiempos de ilusiones y dulce desvarío. No te roce siquiera la piedad, hijo mío.

(Juaristi, 1988: 14-15). 
En este segundo poema, los cambios, todos o casi todos de carácter microtextual, se reparten a lo largo de toda la composición. Obviando el reemplazo de título, en el primer verso ya asistimos a la sustitución de «nostalgia» por el más preciso «piedad» (v. 1), que es en efecto de lo que el poema habla - la que su hijo no debe tenerle, aunque el hecho de que se trata de un poema dirigido al hijo no nos es revelado hasta el vocativo con que la composición se cierra-; parecido a este cambio del verso inicial es el que más tarde lleva a sustituir «madurez» por «rigidez» (v. 15), otra vez afinando algo el sentido, o de «sacaría» por «guardaría» (v. 32), con el mismo resultado. Con todo, los pentimenti de este poema suelen procurar mayor naturalidad expresiva, lo que lleva a cambiar «adviertes sutileza» por «tomas por finura» (v. 8) o «suponía el cuitado» por «pensaba el muy estúpido» (v. 12), que, a fuer de más natural, también es más expresivo; a la misma línea pertenece la modificación del más afectado «mas sucedió que» en el casi coloquial «hasta que un día» (v. 26). Dicho todo esto, no queda claro por qué se corrige «no había nada» en "pues nada había» (v. 9), si no es que, con la alteración del orden de la secuencia se gana una sílaba mediante una sinalefa — «expresión. No había nada de eso» / "expresión, pues nada había de eso»—, lo que permite introducir la conjunción causal «pues», que dulcifica la articulación lógica del verso.

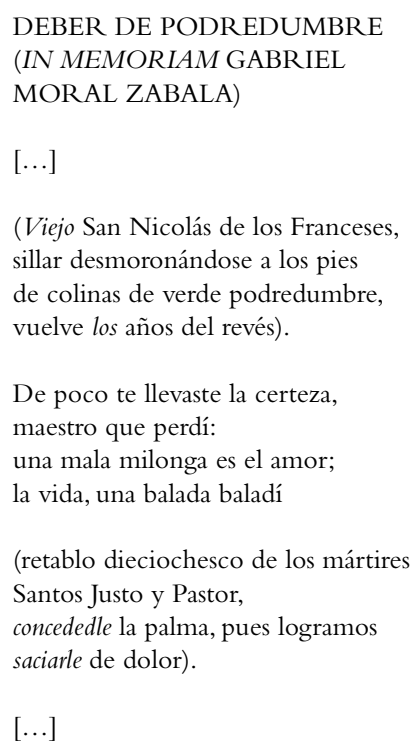

DEBER DE PODREDUMBRE (IN MEMORIAM GABRIEL MORAL ZABALA)

$[\ldots]$

(San Nicolás de los Franceses, sillar desmoronándose a los pies de colinas de verde podredumbre, vuelve mis años del revés).

De poco te llevaste la certeza, maestro que perdí: una mala milonga es el amor; la vida, una balada baladí

(retablo dieciochesco de los mártires Santos Justo y Pastor, devolvedle la palma, pues logramos saciarlo de dolor).

$[\ldots]$ 
Siguiendo con el orden cronológico, y pasando al siguiente libro de Juaristi, podemos ver aquí en primer lugar cómo la primera publicación del poema «Deber de podredumbre» en la revista Renacimiento presentaba un endecasílabo en su v. 4, convertido en eneasílabo en la versión definitiva de Los paisajes domésticos (1992) mediante la supresión del adjetivo "Viejo»; del mismo modo, en el v. 7 un algo más genérico «los años» se ve transformado en "mis años», de modo que la implicación emocional del yo lírico se vea enfatizada. En fin, los vv. 14 y 15 también presentan sendas variantes, pues "concededle» se corrige en «devolvedle»; y «saciarle», en «saciarlo»: si la segunda variación mira a evitar un leísmo - por más que, al ser el de 3. ${ }^{a}$ persona del singular, sea el único admitido por la RAE-, la primera introduce un pequeño matiz de significado que quizá haga el poema una pizca más evocador, por cuanto añade información sobre el pasado de quien se predica, a quien se devuelve algo que ya había tenido, pues, y no solo se le concede. Más allá de estas finezas, no hay más cambios que registrar.

INTENTO FORMULAR MI EXPERIENCIA DE LA POESÍA CIVIL

¡Oh, Capitán, mi Capitán, Dios mío! ¡A por ellos, que son de regadío! Walt Whitman y Ramón Cabrera

Según algún amigo sevillano, cerró hace un siglo aquella librería de Sierpes, donde un día compré su Colección particular.

Mediaba un largo y tórrido verano, pero yo celebré la epifanía.

Dieciocho años tenía y empezaba a sentir el malestar

$[\ldots]$

(Juaristi, 1992a: 4).
INTENTO FORMULAR MI EXPERIENCIA DE LA POESÍA CIVIL

¡Oh, Capitán, mi Capitán, Dios mío!

¡A por ellos, que son de regadío!

Walt Whitman y Ramón Cabrera

Según algún amigo sevillano,

cerró hace siglos aquella librería

de Sierpes, donde un día

compré su Colección particular.

Mediaba un largo y tórrido verano, pero yo celebré la epifanía.

Dieciocho años tenía

y empezaba a sufrir el malestar

$[\ldots]$

(Juaristi, 1992b: 27).

Otro poema emblemático de Los paisajes domésticos fue también adelantado por la revista Renacimiento, órgano periódico de la editorial que acabaría publicando el libro. Nos referimos ahora al conocido «Intento formular mi experiencia de la poesía civil» (Olay Valdés, 2019:29-31; López-Pasarín, 2018): nuevamente, los cambios atañen únicamente a la sustitución léxica de unidades muy próximas en fondo y forma, cercanas en lo fonético y lo significativo. Si el 
original «un siglo» (v. 2) se ve incrementado en el definitivo «siglos», otro tanto sucede con el inicial «sentir» (v. 8), corregido finalmente en el más marcado «sufrir».

\section{COMENTARIO DE TEXTO}

En la tarde de enero, casi vacía el aula, mientras la lluvia roe el frágil pavimento del campus, en voz alta más alta por la falta de auditorio, declamas poemas de Aire Nuestro.

¿Qué les dirás después a estas frentes estólidas, flor de fin de milenio,

que por algún milagro han consentido en venir hoy a clase o que, sencillamente, permanecen aquí desde hace una semana para evitar mojarse o porque nada mejor tienen que hacer hasta el año que viene? ¿Apreciarán la tersa palabra, el verso escueto, conciso, exacto, austero, el lenguaje hecho médula,

la precisión soberbia con que plasmó la vida en secos fogonazos?

De otra tarde te acuerdas: Clamor, leído en grupo a la orilla del Cares, y de aquel profesor de tu bachillerato -Agustín - que decía: «Todo está bien. Dejadlo como está». Ha pasado más de un cuarto de siglo.

Déjalo como está. Que el bedel vespertino te libre del delirio de intentar lo imposible.

Un poema a sí mismo se comenta.

Lo demás solo es ruido:

"Aprender, enseñar, lecciones, aulas».

(Juaristi, 1993a: 93-94).

\section{COMENTARIO DE TEXTO}

A Agustín Arquer

En la tarde de enero, el aula a media entrada, mientras la lluvia roe el frágil pavimento del campus, en voz alta más alta por la falta de auditorio, declamas poemas de Aire Nuestro.

¿Qué les dirás después a estas frentes estólidas, flor de fin de milenio,

que por algún milagro han consentido en venir hoy a clase o que, sencillamente, permanecen aquí desde hace una semana para evitar mojarse o porque nada mejor tienen que hacer hasta el año que viene? ¿Apreciarán la tersa palabra, el verso claro, conciso, exacto, austero, el lenguaje hecho médula,

la precisión soberbia con que plasmó la vida en secos fogonazos?

De otra tarde te acuerdas:

Clamor, leído en grupo a la orilla del Cares, $\mathrm{y}$ de aquel profesor de tu bachillerato

-Agustín- que decía: "Así está bien. Dejadlo como está». Ya ha pasado más de un cuarto de siglo.

Déjalo como está. Que el bedel vespertino te libre del delirio de intentar lo imposible. El poema despliega su propio comentario, $y$ lo demás es ruido:

"Aprender, enseñar, lecciones, aulas».

(Juaristi, 1996a: 34-35).

Más enjundia revisten las modificaciones insertas por Juaristi en el poema "Comentario de texto", publicado primero en 1993 en Revista de Occidente y más tarde reunido en la colección Tiempo desapacible. En la emblemática publicación periódica falta, en primer lugar, la dedicatoria definitiva a Agustín Arquer, que hubiera resultado extraña en el número de la revista, consagrado al homenaje de Jorge Guillén y aparecido con motivo del centenario del poeta. Por lo demás, Arquer es aludido en el poema, no solo por su nombre propio (v. 23), sino en lo referido a sus lecciones. Arquer, por cierto, 
es un personaje clave para Juaristi, quien lo alude en sus memorias repetidamente (Juaristi, 2006: 191-194, 206) y quien le brindó un sentido obituario (Juaristi, 2007: 16). De hecho, en un poema adelantado por la revista Anáfora, titulado «2017» (Juaristi, 2018b: 5), Arquer recibe nuevo homenaje. Sea como fuere, tanta insistencia en este viejo maestro del poeta bilbaíno está justificada porque, más allá de la sustitución de "casi vacía el aula» por el menos automático «el aula a media entrada» (v. 2), y más allá del reemplazo del adjetivo «escueto» (v. 16) por «claro», lo que parece un acierto cuenta habida de que la lección original parece redundar a la luz de otros adjetivos inmediatos como «conciso» o «austero» (v. 17), los principales cambios entre ambas versiones se concentran en resumir las palabras de Arquer. Según Juaristi, «la aportación más valiosa de Agustín Arquer consistió en revelarnos la condición de artefacto del texto literario", pues «un poema no es un milagro, sino una construcción verbal». Así, «la insistencia en el comentario de los textos [...] nos resultó al principio árida, pero pronto comprendimos su utilidad» — repárese en el título del poema- Finalmente, Arquer «buscó familiarizarnos con una poesía seca, intelectual, difícil», especialmente con «Salinas y Guillén» (Juaristi, 2006: 193). Queda clara, de esta forma, la vinculación entre Arquer y Guillén que el poema explota; más allá de ello, la expresión «Todo está bien» (v. 23), puesta en palabras de Arquer, se redondea con el definitivo "Así está bien», más natural y exacto si de coloquialidad hablamos. El prístino «Ha pasado» (v. 24) se ve acertadamente enfatizado con el «Ya ha pasado» publicado en libro. Por último, en los vv. 27-28, la paráfrasis es completa, de suerte que el más sintético y ambiguo «Un poema a sí mismo se comenta» inicial (v. 27) se aclara en "Un poema despliega su propio comentario», otra vez más fácilmente imaginable en labios del personaje; por fin, la variación del verso siguiente ya es solo sintáctica, sin otras implicaciones. En resumen, los cambios pretenden hacer más verosímiles las palabras del personaje poemático de Arquer — al tiempo que deshacen ciertas redundancias- o extraer las necesarias notas de extrañamiento de ciertas expresiones. 
DOS CIUDADES

\section{A Inmaculada}

La ciudad donde vivo, como España, limita al norte con el mar Cantábrico. La tuya está enclavada en un terrón brumoso. Pone el frío a sus puertas un lobo estremecido. La despueblan los tristes cristales del invierno.

Mi ciudad ya no es mía.

Cortaron mis raíces, si alguna vez las tuve. No sabría decir por qué no la abandono, por qué retorno al cabo de errancias sin sosiego, sabiendo -eso lo sé- que nadie aquí me espera.

Yo viajo a tu ciudad dos veces por semana. Al trasponer el puerto, cuando a mi espalda quedan los ríos moribundos las parroquias que albergan camadas de asesinos, una canción estalla entre mis dientes.

Tu ciudad ya es un hábito.

La ciudad en que habito me será siempre ajena como un amor anónimo de noche enloquecida. Suena a bolero amargo la calle en que nací.

Cada esquina acuchilla mi memoria.

En tu ciudad hasta la nieve abriga.

Paseo por sus plazas contigo de la mano.

Sin prudencia te beso frente a su catedral.

Mi ciudad me lacera infatigable.

No sé por qué regreso dos veces por semana.

(Juaristi, 1993b: 33).
DOS CIUDADES

La ciudad donde vivo, como España, limita al norte con el mar Cantábrico. La tuya está enclavada en un terrón brumoso. Pone el frío a sus puertas un lobo estremecido. La despueblan los tristes cristales del invierno.

Mi ciudad ya no es mía.

Cortaron mis raíces, si alguna vez las tuve. No sabría decirte por qué no la abandono, por qué regreso al cabo de errancias sin sosiego, sabiendo, como sé, que nadie aquí me espera.

Yo viajo a tu ciudad dos veces por semana. Al trasponer el puerto, cuando a mi espalda quedan los ríos moribundos, las parroquias que albergan camadas de asesinos, una canción estalla entre mis dientes.

Tu ciudad ya es un hábito.

La ciudad que yo habito me será siempre ajena como un amor anónimo de noche enloquecida. Suena a bolero amargo la calle en que nací. Cada esquina acuchilla mi memoria.

En tu ciudad hasta la nieve abriga.

Paseo por sus plazas contigo de la mano. Sin prudencia te beso frente a su catedral. Mi ciudad me lacera infatigable.

No sé por qué regreso dos veces por semana.

(Juaristi, 1996a: 38-39).

En este poema, asistimos una vez más a un caso parecido. Los mínimos ajustes léxicos, de nuevo entre unidades fonética y semánticamente muy próximas, consisten en la sustitución consecutiva de «decir» por «decirte» (v. 8), «retorno» por «regreso» (v. 9) y «—eso lo sé-》 por «como sé» (v. 10); solo unos versos más abajo, también de «ciudad en que habito» por «ciudad que yo habito» (v. 16). El primer y último cambios tratan de conseguir una mayor implicación del locutor con su discurso; los otros tres, decantar la lengua del poema en pos de una mayor naturalidad. Al margen queda la dedicatoria de la versión publicada en revista, después desaparecida; por su carácter paratextual, es un cambio extraliterario que, a diferencia de lo que sucedía en la dedicatoria anterior a Agustín Arquer, ya no nos compete ni sabríamos estudiar.

Pasando ahora a los poemas incluidos en Prosas (en verso), la delicada canción «Maestu» fue originalmente adelantada en la revista 
Clarín, sin que nos quepa observar ningún cambio más allá de que la versión definitiva lee «sombra de garza» (Juaristi, 2002:17) donde el original decía «sombras de garza» (v. 14) (Juaristi, 1996b: 34). La sustitución, de tan leve, apenas merece comentario, aunque es cierto que la lección definitiva subraya la simetría con el inmediatamente anterior v. 13, «sobre las ondas», ya que, en singular, el sustantivo «sombra» se asemeja más a la preposición «sobre».

DAMA DE ELCHE

\section{A Luis Alberto de Cuenca}

Radiotelefonista con legañas, mutilada de guerra que, al descuido, por la silla de ruedas se ha escurrido o Fallera Mayor de las Españas,

como sé que la fe traga montañas, que el amor al solar — si desmedidoal más dulce varón nubla el sentido, y se forjan las patrias con patrañas,

como toda prudencia siempre es poca y aún diría que nada en lo que toca al honor de este pueblo suspicaz,

íngrima dama ibérica, me obstino en comulgar tus muelas de molino, prendas de una precaria España en paz.

(Juaristi, 1997: 46)
DAMA DE ELCHE

\section{A Luis Alberto de Cuenca}

Radiotelefonista con legañas, mutilada de guerra que, al descuido, por la silla de ruedas se ha escurrido o Fallera Mayor de las Españas,

como sé que la fe mueve montañas, que el amor al solar, si desmedido, al más dulce varón turba el sentido, y que se forjan patrias con patrañas,

como toda prudencia siempre es poca y aún diría que nada en lo que toca al honor de este pueblo suspicaz,

íngrima dama ibérica, me obstino en comulgar tus ruedas de molino, prendas de una precaria fiesta en paz.

(Juaristi, 2002: 39).

El soneto «Dama de Elche» es otro de los casos de estudio más interesante, siempre dentro de este tipo de cambio fundamentalmente epidérmico que caracteriza el taller de Juaristi. El poema, vuelta de tuerca del autor sobre el tema de España (Iravedra, 2014), concentra sus variantes en el segundo cuarteto y el segundo terceto. En el primer caso, el más extrañado «traga montañas» (v. 5) se resuelve en el más natural «mueve montañas» de la versión publicada en libro, en tanto que lo contrario sucede con «nubla el sentido» (v. 7), que se reemplaza por el menos previsible «turba el sentido». El cambio de sintaxis del v. 8, que pasa de "y se forjan las patrias con patrañas» a «y que se forjan patrias con patrañas», busca ubicar todos los predicados del cuarteto al mismo nivel sintáctico, como sucesivas completivas del verso principal «sé» (v. 5): «sé que la fe traga...», «que el amor al solar..." y "que se forjan patrias...», lo que resultaba más confuso en la primera redacción. Por su lado, en el segundo terceto, 
la aliterativa secuencia «en comulgar tus muelas de molino» (v. 13), de evidente recurrencia nasal, pasa al menos perfecto «en comulgar tus ruedas de molino", donde sin embargo la locución comulgar con ruedas de molino ('creer lo más inverosímil o los mayores disparates') aparece claramente enunciada y no in absentia. En fin, la también aliterativa "precaria España en paz» (v. 14) de la versión primera se disuelve en "precaria fiesta en paz», elidiendo el nombre propio clave (ya presente en el v. 4) y haciendo visible otra vez la locución «fiesta en paz», anteriormente solo insinuada. Como se ve, los cambios de este soneto tienden a salvar traslaciones significativas o esguinces conceptistas que cumple definir como violentos en aras de una mayor sencillez, aunque ello haga resentirse determinados juegos paronomásicos.

RESTAURANTE CHINO

Por favor, no te vayas.

Espera a que acabemos la Familia Feliz.

Come un poco de Pato Lacado y de Chop Suey.

No me pongas, amor, en evidencia

ante la concurrencia.

Pero, si quieres, huye,

déjame.

Daré cuenta yo solo de esta cena agridulce.

Cuando tú te hayas ido, me envolverán las sobras.
RESTAURANTE CHINO

Por favor, no te vayas.

Espera a que agotemos la Familia Feliz.

No me pongas, amor, en evidencia

ante la concurrencia.

Pero, si quieres, huye,

déjame.

Daré cuenta yo solo de esta cena agridulce.

Cuando tú te hayas ido, me envolverán las sobras.

(Juaristi, 2008b: 3).

(Juaristi, 2012: 25).

Muchos más, hasta media docena, fueron los textos adelantados por Juaristi del que más tarde sería el último de sus libros, Renta antigua. En "Restaurante chino» se decide a eliminar un verso completo, el tercero, seguramente porque su inclusión difuminaba, con la mención de otros platos típicos orientales ("pato lacado», «chop suey»), la alusión a esa anfibológica «Familia Feliz» (v. 2), que no solo es la del yo poético, sino también la receta compuesta por 'ternera y pollo, frutos del mar, vegetales como zanahoria y tallos de bambú y salsa de soja'. Por encima de esta supresión, el verbo del v. 2 pasa de «acabemos» a "agotemos»; si la opción original se relaciona más claramente con el sentido culinario de «Familia Feliz», la segunda mira a su otra interpretación, de cariz sentimental. En definitiva, los dos cambios operados pretenden insistir en la carga sentimental del texto. Por lo demás, ya al margen de estas variantes de autor, el 
último verso del poema modifica un pasaje de una conocida canción de Alberto Cortez, pero donde el argentino cantaba «Cuando tú te hayas ido, / me envolverán las sombras» (de la canción Cuando tú te hayas ido) - para este tipo de recursos juarísteos, véase Leuci (2016) — Juaristi reemplaza «sombras» por «sobras» de acuerdo con la isotopía gastronómica del poema.

\section{LIGERO DE EQUIPAJE}

Mi boina azul de Elósegui. Acuarelas, pinceles. Botas de Timberland que miman los pinreles. Un Barbour desgastado. La mochila de cuero comprada en Greenwich Village a un buen talabartero:

fiel compañera mía desde hace quince años, no es de marca famosa, mas no presenta daños después de tantos lustros de marcha, sino lustre de vientos, soles, lluvias y de bruma palustre. La bufanda Burberry. Tres cartones de Vogue. Un peine de carey, termómetros de azogue. Dos o tres diccionarios y algunos moleskines. Boxers, T-shirts, pijamas, pastillas, calcetines. Rocalla y espejuelos en cantidad discreta para cambiar por pieles de nutria o de poeta. Una Höhner cromática, una balsa neumática, un puño americano, mi navaja automática. Una guía de Estonia, prismáticos y lentes, mi panda de peluche, mi cepillo de dientes, Cuando parta la nave que nunca ha de tornar, me encontraréis a bordo (si logro facturar).

(Juaristi, 2008b: 3)

\section{LIGERO DE EQUIPAJE}

Mi boina azul de Elósegui. Acuarelas, pinceles. Botas de Timberland que miman los pinreles. Un Barbour desgastado. La mochila de cuero comprada en Greenwich Village a un buen talabartero:

fiel compañera mía desde hace veinte años, no es de marca famosa, mas no presenta daños después de tantos lustros de marcha, sino lustre de vientos, soles, lluvias y de bruma palustre. La bufanda Burberry. Los cartones de Vogue. Un peine de carey, termómetros de azogue. Dos o tres diccionarios y algunos moleskines. Boxers, T-shirts, pijamas, pastillas, calcetines. Rocalla y espejuelos en cantidad discreta para cambiar por pieles de nutria o de poeta. Una Höhner cromática, una balsa neumática, un puño americano, mi navaja automática. Una guía de Estonia, prismáticos y lentes, mi hiena de peluche, mi cepillo de dientes, $y$ así que parta el $A V E$ que nunca ha de tornar, me encontraréis a bordo después de facturar.

(Juaristi, 2012: 17).

Algún cambio más se advierte en «Ligero de equipaje», poema de título machadiano en el que acaso no todas correcciones mejoren el texto. Los «quince» años del v. 5 cuando el poema se publica en revista en 2008 se convierten en "veinte» cuando el texto aparece definitivamente en libro en 2012, lo que tiene toda la coherencia cronológica. A su vez, los «tres cartones» de Vogue (v. 9) originales, se convierten más genéricamente en «los cartones», quizá por la arbitrariedad del numeral, por buscar una mayor indeterminación o por evitar la repetición de la palabra, pues «tres» ya son los «Diccionarios» del v. 11, y sucede que el resto de los objetos citados en plural siempre se aluden en número indeterminado: «acuarelas, pinceles» (v. 1), «termómetros de azogue» (v. 10), "algunos moleskines. / Boxers, T-shirts, pijamas, pastillas, calcetines» (vv. 11-12), etc. Se entiende también el cambio del v. 18, donde el más átono "panda de peluche» inicial se convierte en una «hiena 
de peluche», mucho más consecuente con el personaje poético que protagoniza los poemas de Juaristi, al que sus enemigos caracterizan como traidor o desertor (Díaz de Castro, 2002; Juaristi, 2008a: 45; y, especialmente, Leuci, 2017); y lo mismo ocurre con ese machadiano «Cuando parta la nave que nunca ha de tornar» de la versión publicada en revista (v. 19), trasformado paronomásticamente, con un uso sintáctico arcaizante, en "y así que parta el AVE que nunca ha de tornar». No es de hecho esta la única ocasión en que los trenes españoles de alta velocidad sirven a Juaristi para urdir un juego conceptista (véase «Mar de Castilla», v. 36 [Juaristi, 2002: 16]). Sin embargo, la versión definitiva del verso final, «después de facturar» (v. 20), arruina el chiste original, «si logro facturar», en referencia a que la enorme cantidad de objetos listados hacen al sujeto de todo menos lo que el título del poema proclama, y aun compromete el hecho de que el viajero sea admitido a bordo de la «nave» —o del «AVE»-, dadas las restricciones de equipaje que hoy caracterizan casi todos los medios públicos de locomoción.

APHASIA

Con creciente frecuencia,

la maldita memoria se encasquilla

y busco en vano nombres

para rostros que surgen

de la marisma pétrea del sueño.

Esas sombras anónimas regresan al olvido, no $\sin$ antes dejarme

un rastro de ceniza en la mirada.

Así será mi muerte, lo presiento: no encontraré partidas de bautismo, diplomas escolares,

cartas que me demuestren que fui amado.

Cuando ni una palabra me convenga, vendrá y tendrá tus ojos

o los de otra.

(Juaristi, 2008b: 5).

\section{AFASIA}

Con creciente frecuencia,

la maldita memoria se encasquilla

y busco en vano nombres

para rostros que surgen

de la marisma pétrea del sueño.

Esas sombras anónimas regresan al olvido, no sin antes dejarme

un rastro de ceniza en la mirada.

Así será mi muerte, lo presiento: no encontraré partidas de bautismo, diplomas escolares,

cartas que me demuestren que te importé algún día.

Cuando ni una palabra me convenga, vendrá y tendrá tus ojos o los de otra cualquiera.

En este nuevo caso, los cambios, muy menores, se centran en los compases finales del poema, además de en su título, que abandona la transcripción latina del original griego para simplificarse en el más connatural español. El endecasílabo que en origen es el v. 12, "cartas que me demuestren que fui amado", se expande en el más coloquial y modesto alejandrino «cartas que me demuestren que te 
importé algún día”, al mismo tiempo que el también endecasílabo escindido "vendrá y tendrá tus ojos / o los de otra» (vv. 14-15), se traspone en el alejandrino o suma de heptasílabos «vendrá y tendrá tus ojos / o los de otra cualquiera». Esta segunda lectura es más natural, porque la versión de once sílabas «vendrá y tendrá tus ojos o los de otra» fuerza una sinalefa impropia (Balbín, 1968:75-76) en el

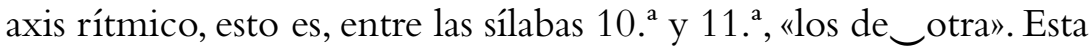
sinalefa se mantiene en el alejandrino, pero ya no en una posición tan crucial, de modo que ya no resulta cacofónica o, siquiera, violenta. En suma, los cambios propuestos, pese a su levedad, tienden a rebajar el tono del poema y a hacerlo discursivamente más conversacional, en consonancia con lo observado en otros poemas.

TOMÁS BILBAO HOSPITALET, MINISTRO DE LA SEGUNDA REPÚBLICA ESPAÑOLA, DESEMBARCA ENVERACRUZ (22 DE MAYO DE 1942)

\section{A Marina Pino}

El sueño del exilio produce fantasías aflictivas $y$ lúgubres. La tierra que te has dejado arrebatar no volverá a ser tuya (quizá nunca lo fue, y el destierro confirme una carencia que equivocadamente tomaste por arraigo).

Es cierto que los tuyos

a ella pertenecían, y les pertenecía un trozo del país del que es metáfora un sepulcro atestado,

pero tú,

el apóstol escéptico que partió hacia poniente,

Quetzalcóatl, cuyo rastro se ha borrado hasta de los archivos del odio inextinguible, nunca reposarás entre los huesos de gentes de tu nombre.

En extranjera playa vas soltando

las piedras blancas que te indicarían la más segura ruta de retorno en un cuento cualquiera de brujas alemanas, pero que, en este caso, por desgracia tan poco literario, solo llevan al mar, que es el morir.

Fantasmas de humo las banderas tristes, y el inconcluso amor, un trampantojo.
TOMÁS BILBAO, MINISTRO DE LA SEGUNDA REPÚBLICA ESPAÑOLA, DESEMBARCA EN VERACRUZ, EL 22 DE MAYO DE 1942

\section{A Marina Pino}

El sueño del exilio produce fantasías inútiles. La tierra

que te has dejado arrebatar no volverá a ser tuya (quizá nunca lo fue, y el destierro confirme una carencia que equivocadamente tomaste por arraigo).

Es cierto que los tuyos

a ella pertenecían, y les pertenecía un trozo del país del que es metáfora un sepulcro atestado, pero tú,

el apóstol escéptico que partió hacia poniente, Quetzalcóatl, cuyo rastro se ha borrado hasta de los archivos del odio inextinguible, nunca reposarás entre los huesos de gentes de tu nombre.

\section{En extranjera playa vas soltando}

las piedras blancas que te indicarían la más segura ruta de regreso en un cuento cualquiera de brujas alemanas, pero que, en este caso, por desgracia tan poco literario, solo llevan al mar, que es el morir.

Fantasmas de humo las banderas tristes, $\mathrm{y}$ el inconcluso amor, un trampantojo.

(Juaristi, 2012: 29-30). 
Algo parecido se observa en el poema situado sobre estas líneas, en el que todos los cambios tienden a rebajar el tono, disolviendo nudos de alto coturno en pos de soluciones más coloquiales. Primero, en el título, se suprime el segundo apellido del personaje protagónico y se añade al periodo oracional la fecha en que los acontecimientos suceden, aislada parentéticamente en la versión publicada en revista. La bimembración "aflictivas y lúgubres» (v. 2), en verso endecasílabo, pasa a «inútiles» y a la mayor sencillez del heptasílabo, del mismo modo que «retorno» (v. 19) se atenúa en «regreso». No hay más cambios en este poema, que versifica una de las páginas de las memorias familiares de Juaristi, $A$ cambio del olvido, escrito al alimón con María Pino (Juaristi y Pino, 2010: 442).

CONTRA JOHN FORD

... and go to Innisfree...

W. B.YeATS

¿Regresar a Innisfree, pueblo querido, con un borracho en cada puerta, el IRA mandando en las tabernas y la tira de cabrones que llevan tu apellido?

¿Unirte a tal rebaño resentido? ¿Procurar que te manden a la pira? $¿$ Es eso a lo que aspira

tu cerebro irlandés o reducido?

Séan Thornton: el mundo está lleno de dulces pelirrojas

lejos de aquel rincón nauseabundo,

¿por qué, entonces, te amargas y acongojas, y en la añoranza pierdes un segundo de verdes valles y colinas rojas?

(Juaristi, 2008b: 4).
CONTRA JOHN FORD

... and go to Innisfree...

W. B.YeATS

¿Regresar a Innisfree, rincón querido,
con cien borrachos por familia, el IRA
mandando en las tabernas y la tira
de cabrones que llevan tu apellido?
¿Unirte a tal rebaño resentido?
¿Procurar que te manden a la pira?
¿Es eso a lo que aspira
tu cerebro irlandés o reducido?
Si abundan en el mundo
las solteronas tiernas, dulces, flojas,
de natural pacífico y jocundo,
¿por qué, entonces, te afliges y acongojas,
y en la añoranza pierdes un segundo
de verdes valles y colinas rojas?

(Juaristi, 2012: 27).

Más modificaciones notamos en «Contra John Ford», subversión de la película El hombre tranquilo, dirigida por este. De hecho, cabe incluso hablar de reescritura, al menos en el primer terceto. Un chato «pueblo querido» (v. 1) pasa a ser «rincón querido», sintagma sin duda menos automatizado, si bien el también inicial «con un borracho en cada puerta» resulta más visualizable y concreto que el definitivo "con cien borrachos por familia», al que afea el ripioso numeral cien que, por monosílabo y cuantioso, tan socorrido resulta en manos de los poetas. Sí parece acertada la aliterada solución «afliges y acongojas» (v. 12) donde el original leía «amargas y acongojas». Con todo, 
la reescritura es total en el primer terceto. El v. 9 original, «Séan Thornton: el mundo", suena trunco en cuanto al número, pues tiene seis sílabas en lugar de las siete necesarias para combinarse con los endecasílabos en un soneto polimétrico. Una lectura castiza y cómica que haga «Séan» palabra bisílaba, pronunciada a la española, parece disonar del tono del poema, de modo que al menos métricamente este verso original parece peor que el definitivo «Si abundan en el mundo». Ahora bien, el directo vocativo "Séan Thornton» también hacía más claro y comprensible el destinatario del poema - Thornton es el boxeador retirado que, interpretado por John Wayne, protagoniza la película que sirve como marco referencial del poema-, del mismo modo en que lo hace el v. 11 de la primera versión del soneto, «lejos de aquel rincón nauseabundo». La idea está clara: Séan Thornton sería una proyección del yo poético a quien, sin embargo, este se dirige con objeto de recomendarle que no regrese a Innisfree, topónimo irlandés encumbrado por W. B.Yeats que aquí actúa como evidente transposición literaria del PaísVasco, pues, no en vano, el poema habla de la imposibilidad del locutor poemático de regresar a su Euskadi natal - los vv. 3-4, en esta línea, podrían estar aludiendo a personas como Josu Juaristi, eurodiputado del partido abertzale EH Bildu-. Al fin y a la postre, la imposibilidad del regreso es uno de los temas principales de la poesía de Juaristi desde Prosas (en verso) en adelante, esto es, desde que trasladase su residencia a Madrid - léanse, por caso, los poemas «Zortziko para Mikel Azurmendi» (Juaristi, 2002: 43-44) o «Póntica» (Juaristi, 2008a: 7)—. Volviendo por donde íbamos, la supresión del vocativo del v. 9 y de la formulación directa del tema del poema en el v. 11 hacen la versión definitiva más inconcreta, pero, a la vez, mejor rítmicamente, pues ya hemos dicho que el v. 9 original cojea en cuanto a su cómputo silábico y algo parecido sucede en el v 11, en que es necesario leer «nauseabundo» como pentasílabo en lugar de como tetrasílabo, lo que resulta levemente antinatural. Por fin, el inicial v. 10, «está lleno de dulces pelirrojas», en transparente alusión ahora a Maureen O'Hara, que interpreta el papel de la pelirroja Mary Kate Danaher — esposa de Thornton al final de El hombre tranquilo- se ve reemplazado por el endecasílabo «las solteronas tiernas, dulces, flojas», en que una vez más se diluye la referencia cultural que se ve que ha armado el poema y en que aparece esa trimembración adjetiva acaso levemente redundante. En suma, otra vez los cambios buscan simplificar tenuemente el contenido del poema haciendo desaparecer ahora ciertas referencias culturales. 


\section{VEINTICINCO PLUVIOSO}

A la memoria de mi amigo Francisco Tomás y Valiente, tras su muerte republicana.

De la vida en común desconocemos el fundamento último. Teorías más o menos vienesas lo sitúan en la viril parranda que siguió a un parricidio arcaico. Sin embargo,

nadie ha logrado aún fijar el texto del pacto que arrancó, según las antedichas, a una banda de monos aterrados del torpe estado de naturaleza ni definir los términos exactos — para ser más exactos, presemióticosdel convenio en que arraiga la lengua quebradiza con que nos esforzamos en cubrir el silencio fragoroso del mundo.

Tan durable ignorancia no permite alimentar piadosas ilusiones. Apenas nos separan dos palmos de mantillo del hacha solutrense y erguidas permanecen murallas que exigieron cimentación de huesos y sangre en la argamasa. Piedad, lo que se dice piedad, nunca la hubo para los que caían bajo la glauca bóveda del bosque originario.

Esto solo sabemos: que las generaciones marchan hacia la noche ungidas por la pólvora. Que a todas horas zarpan navíos sin retorno. Que cualquier estación es tiempo de asesinos.

Pero en los días sucios del terror a visitarnos vuelve la memoria de alguno que escogió resistir, a trueque de la vida. Percibimos un brillo lejano y tembloroso, y se va abriendo paso la certeza de un destino posible a través de este tiempo de antiguo encabritado. Como el del torbellino fugaz en la tormenta, un destino mortal y, con todo, un destino más querido, más libre, más alto, más valiente.

(Juaristi, 1996b: 35).

\section{VEINTICINCO PLUVIOSO}

A la memoria de Francisco Tomás y Valiente

De la vida en común desconocemos el fundamento último. Teorías más o menos vienesas lo sitúan en la viril parranda que siguió a un parricidio arcaico, celebrado en estricta y cordial intimidad. Nadie, con todo, supo entonces ni ha sabido después fijar la fecha del linchamiento de Papá, único plato del menú del día en que algunos monitos aterrados emergieron de golpe a la conciencia, al rito y a la ley $y$ a los deleites del vicio y la virtud. Nadie tampoco ha descrito los términos exactos (para ser más exactos, presemióticos) del contrato en que arraigan las lenguas tornadizas con que nos esforzamos en cubrir el silencio fragoroso del Ser.

Tan tenaz ignorancia no permite alimentar piadosas ilusiones: apenas nos separan dos palmos de mantillo del Hacha Solutrense

y erguidas permanecen murallas que exigieron cimentación de huesos y sangre en la argamasa. Piedad, lo que se dice piedad, nunca la hubo para los que cayeron

bajo la glauca bóveda del bosque originario.

Esto solo sabemos: que las generaciones marchan hacia la noche ungidas por la pólvora, que en el alba agonizan rebaños de inocentes, que a todas horas zarpan navíos sin retorno, que cualquier estación es tiempo de asesinos.

Pero, en los días sucios del Terror, a visitarnos viene la memoria de alguno que escogió resistir a trueque de la vida. Atisbamos un brillo de estrellas temblorosas, y se va abriendo paso la certeza de un destino posible a través de este tiempo de antiguo encabritado: un destino mortal y, no obstante, un destino más querido, más libre, más alto, más valiente. 
En último lugar ubicamos un poema al que no le correspondería esta posición en términos cronológicos, pero que hemos dejado para el final por ser aquel en que más cambios se han operado entre la versión aparecida en revista, en este caso en Clarín, y su definitiva inclusión en Prosas (en verso). Como es sabido, Francisco Tomás y Valiente fue asesinado por la banda terrorista ETA el 14 de febrero de 1996; el poema de Juaristi se publicó por vez primera en el número de noviembre-diciembre de ese mismo año de la citada revista ovetense, solo unos meses después, por tanto, del terrible acontecimiento. Eso, unido a la densidad conceptual del poema, explica, en fin, que esta fuese solo una primera tentativa provisional y que, en el momento de su publicación en libro, seis años después, en verano de 2002 según el colofón de Prosas (en verso) (Juaristi, 2002: 93), los cambios fuesen notables.

Primeramente, observamos cómo la dedicatoria se simplifica, pues la alusión a «mi amigo» y a su "muerte republicana» desaparecen - Tomás y Valiente fue asesinado en su despacho de la Universidad Autónoma de Madrid - (Juaristi, 2006:385).A renglón seguido, hay diferentes cambios de puntuación, ortografia y disposición versal en este poema-ensayo: véanse el cambio de paréntesis por guiones largos en el original v. 11, la proliferación de mayúsculas en lo que primero fueron vv. 18 o 29, o la alteración versal de un texto por lo demás idéntico en los vv. 21-22. También hay, claro está, pequeños ajustes de detalle: por ejemplo, la sustitución léxica de «convenio» (v. 12) por "contrato» (v. 17), y de singular por plural en esos mismos versos; de «mundo» (v. 14) por «Ser» (v. 19); o de tiempo verbal en «caían» (v. 23) por «cayeron» (v. 27). Asimismo, el original «Percibimos un brillo lejano y tembloroso" (v. 32) se parafrasea en el más concreto "Atisbamos un brillo de estrellas temblorosas» (v. 37) en la versión incluida en libro. Por encima de estos ajustes, la redacción definitiva añade cinco versos nuevos en la primera estrofa («en estricta y cordial intimidad. / Nadie, con todo, supo entonces / ni ha sabido después fijar la fecha / del linchamiento de Papá, / único plato del menú del día», vv. 6-10) y uno más, de enorme fuerza, en la tercera («que en el alba agonizan rebaños de inocentes», v. 31), pero también suprime otro en la cuarta («Como el del torbellino fugaz en la tormenta», v. 36).

El caso que acabamos de examinar es extraordinario en la medida en que, tal como hemos venido viendo, los cambios que Juaristi suele introducir en sus textos son menores y atañen casi siempre a 
pequeños ajustes que no modifican la índole profunda del poema. Precisamente de este tipo son las modificaciones que podemos observar en Derrotero con respecto de sus compilaciones precedentes. $Y$ es que, como adelantábamos, hasta el momento el texto ofrecido en las dos poesías reunidas publicadas por Juaristi (1994 y 2000) coincidía con el de sus libros exentos - no tengo en cuenta de ahora en adelante los anticipos de poemas sueltos en revistas-. Sin embargo, en su poesía reunida en prensa el poeta ha introducido los siguientes cambios. Bajo el título de cada poema, reproduzco la lección que Juaristi da ahora por buena (en prensa) y, tras un corchete de cierre, la que venían ofreciendo sus libros y poesías reunidas. Sigo con ello el modelo más usual de aparato crítico positivo (Blecua, 1983: 147-148).

Variantes de autor en Derrotero (Poesía reunida, 1969-2019)

Diario del poeta recién cansado

«Trenos de Vinogrado, II»

v. 1 Ha enrojecido la uvayema] Ha enrojecido la yedra

«New Year's Eve (a balance)»

v. 2 and smoked two packs of Winston (Churchill)] and smoked two boxes of Winston (Churchill)

Suma de varia intención

«Tonton Macoute»

v. 10 Más que vosotras] Más que las otras

«Upanishad» aparece ahora tras «Vinogrado revisited»; en las ediciones anteriores, tras «Versos sencillos»

«El gas de mi mechero»

v. 23 porque yo entonces me creía honrado] porque yo entonces me creía bueno

«Campos de Oaxaca» 
v. 7 de pechos hermosísimos] de pechos hermosísimos, en cuclillas,

«Lauretta»

v. 2 ya perdieron su flor los jacarandas] ya perdieron su flor los jacarandáes

Arte de marear

«Última soledad»

v. 4 miró sobre los días borrascas y aluviones] miró sobre los días nevascas y aluviones

«Los tristes campos de Troya»

v. 110 (y es suponerle mucho), subteniente] - y es concederle mucho- subteniente

Los paisajes domésticos

«Poética freudiana»

v. 4 desparrama tu voz en otras voces] desparrama tu voz en muchas voces

v. 12 No hay extensión que pueda con tu herida] No hay cicatriz que pueda con tu herida

«Baztán»

v. 10 como el ávido neblí] como un ávido neblí

Tiempo desapacible

«Romanza con sordina»

v. 13 Ya de regreso a casa, si evocaba] Ya de camino a casa, si evocaba

Prosas (en verso)

«Elogio del Ferrón» 
vv. 13-14 No cantará mejor la flor del agua / que la flor del martillo de su fragua] No cantará mejor la voz del agua / que la voz del martillo de su fragua

Viento sobre las lóbregas colinas

«Estos días azules»

vv. 11-12 Estos días azules, / este sol de la infancia] Este sol de la infancia, / estos días azules

«Para nunca volver»

v. 9 ni aun pujando los dos, hombro con hombro] aun pujando los dos, hombro con hombro

«Adiós, muchachos»

v. 48 aleixandres inconcretos] aleixandres inconexos

«Luis Alberto de Cuenca»

vv. 6-7 de que siempre admiré tu inteligencia, / mas me faltaron dotes y paciencia] de que siempre plagié tu inteligencia, / pero no tuve dotes ni paciencia

v. 13 y ya que no Milú — que más quisiera-] y ya que no Milú —qué más quisiera-

«Décimas de fiebre»

v. 4 sus penas y sus desgarros] sus fobias y sus desgarros

«Juzgado de Familia»

vv. 5-8 Declálese implocedente. / Allá en el Extlemo Oliente, / donde no hay chinito bobo, / la plopiedad es un lobo] Declárese improcedente. / Allá en el Extremo Oliente, / donde no hay un chino bobo, / la propiedad es un lobo

«Canción»

v. 3 por entre los panes que junio madura] cruzando los campos que junio madura

\section{Renta antigua}

«Eppure...» aparece ahora tras «Afasia»; en las ediciones anteriores, tras «No es como lo temías» 
«Entre canes entrecanos»

v. 6 ni consiento que me den lecciones] ni tolero que me den lecciones

«Oración chamánica»

vv. 19-24 Luis Alberto de Cuenca / y Prado. // Pero, hablando de prados, / si acaso a parar fuera a tus praderas / rebosantes de búfalos celestes, / por mí, ni te molestes] Luis Alberto de Cuenca. // Pero, si acaso caigo a tus praderas / cruzadas por los búfalos celestes, / por mí, no te molestes

«Dos de mayo»

v. 8 con un gato asomado a una terraza] con el gato asomado a la terraza

v. 35 Recuerdo que pensé: «iMenudo susto!] Recuerdo que exclamé: «iMenudo susto!

v. 83 a tus egregias plantas se aproxima»] a tus plantas egregias se aproxima»

v. 102 de menudos, medianos y magnates] de humildes y medianos y magnates

v. 114 y el héroe que con Hércules se mide] el héroe que con Hércules se mide

v. 163 Un Mal Poema es un poema bueno] El Mal Poema es un poema bueno

«Amor y pedagogía»

v. 39 en no cruzarlas con los miserables] en no cruzarlas con los soplapollas

«Canto de frontera»

v. 31 \& más Finas] ni más finas

v. 83 por la Alfombra] en la Alfombra

v. 169 como Todo sea Patente] si fuera también Patente

v. 219 \& no sabes a qué Puerta] \& no sabes por qué Puerta 
vv. 234-236 nada de Fuego ni Hielo. / Para nada me interesa / una Sauna Finlandesa] nada de Fuego ni Hielo / ni de Cierzo ni Bochorno. / No interesa / una Sauna Finlandesa,

v. 241 ¡Cuánto mejor un Chantaje] Pero mejor un Chantaje

v. 276 hacia el Olvido Rotundo] hacia el Vacío Rotundo

Como se puede observar, los cambios se concentran en sus últimos libros, lo que resulta lógico, pues los textos más antiguos y alejados del autor son también de más dificil intervención, o, dicho metafóricamente, su tinta está ya seca; resumiendo esto con un dato, se proponen diecisiete modificaciones solo en Renta antigua, último libro de Juaristi, y solo alguna más, veintidós, en todos sus demás libros juntos. Se advierte que muchos cambios buscan redondear el cómputo de algún verso: «Ha enrojecido la uvayema» es eneasílabo, lo que encaja mejor en la silva libre impar del poema en «I» de los «Trenos deVinogrado» que el octosílabo precedente «Ha enrojecido la yedra» (Juaristi, 2000: 14), además, el verso que sigue al modificado, «en las paredes de Mallona», es también eneasílabo y el cambio introduce la recurrencia fónica uvayema $\sim$ Mallona; «and smoked two packs of Winston (Churchill)» es un endecasílabo perfecto — según el patrón rítmico español-, mientras que el previo «and smoked two boxes of Winston (Churchill)» era amétrico (2000: 27); «de pechos hermosísimos» es un heptasílabo que otra vez encaja como un guante en la silva del poema "Campos de Oaxaca», mientras que el original «de pechos hermosísimos, en cuclillas» no puede reducirse a patrón claro (2000: 80); no distinto es el caso del impecable verso de once sílabas "ya perdieron su flor los jacarandas», que corrige el más libre «ya perdieron su flor los jacarandáes» (2000: 87).

Pero, sobre todo, como se advirtió, el grueso de correcciones mira a la precisión léxica. El poeta prefiere el más cercano «vosotras» a «las otras» (2000: 65); «honrado», lo que parece más exacto, antes que «bueno» (2000: 75); «borrascas» en vez de «nevascas» (2000: 109); «suponerle» en lugar de «concederle» (2000: 125); «otras» por «muchas» y «extensión» por "cicatriz» (2000: 133) —en este caso creo que sin fortuna, porque se echa a perder el hermoso verso «no hay cicatriz que pueda con tu herida», convertido en el más átono «no hay extensión que pueda con tu herida»—; «regreso» por «camino» (2000: 181); «VOZ» por «flor» (2002: 41); «inconcretos» por «inconexos» (2008a: 30), lo que arruina la malévola recurrencia 
fónica Aleixandre inconexo; «admiré» por "plagié» y "que» por «qué» (2008a: 39); «penas» por «fobias» (2008a: 41); «panes» por «campos» (2008a: 55); «consiento» por «tolero» (2012: 41); «pensé» por «exclamé» (2012: 52); «egregias plantas» por «plantas egregias» (2012: 54); «menudos» por «humildes» (2012: 55), redondeando la aliteración de menudos $\sim$ medianos $\sim$ mangantes; «miserables» por «soplapollas» (2012: 66); «como Todo sea» por «si fuera también» (2012: 75); o «vacío» por «olvido» (2012: 78).

Los ejemplos de reescritura más allá de estos pormenores son mínimos: en los vv. 11-12 de «Estos días azules», se altera el orden de dos versos, que ahora leen «Estos días azules, / este sol de la infancia» donde antes «Este sol de la infancia, / estos días azules» (2008a: 9), esto es, recuperando el orden del evidente y casi literal modelo machadiano; asimismo, en los vv. 5-8 de «Juzgado de Familia» se exagera un juego retórico antes solo insinuado, pues la versión definitiva reza «Declálese implocedente. / Allá en el Extlemo Oliente, / donde no hay chinito bobo, / la plopiedad es un lobo", mientras que en el original decía, más normalmente, «Declárese improcedente. / Allá en el Extremo Oliente, / donde no hay un chino bobo, / la propiedad es un lobo» (2008a: 47); además, Juaristi injiere dos líneas en el poema "Oración chamánica», pues la transición de sus vv. 1924 lee en Derrotero, con conceptismo también algo chocarrero, «Luis Alberto de Cuenca / y Prado. // Pero, hablando de prados, / si acaso a parar fuera a tus praderas / rebosantes de búfalos celestes, / por mí, ni te molestes», si bien el original, más escuetamente, decía «Luis Alberto de Cuenca. // Pero, si acaso caigo a tus praderas / cruzadas por los búfalos celestes, / por mí, no te molestes» (2012: 49); por fin, Juaristi suprime otro verso en el extenso "Canto de frontera», pues la versión definitiva prefiere «nada de Fuego ni Hielo. / Para nada me interesa / una Sauna Finlandesa» allí donde el original cantaba «nada de Fuego ni Hielo / ni de Cierzo ni Bochorno. / No interesa / una Sauna Finlandesa» (vv. 234-236; 2012: 77), eliminando cierzos y bochornos. Incluso en estos casos de mayor variación, la intervención es de poco calado y en ningún caso afecta al sentido general del texto.

Todo ello, en fin, por obviar otro tipo de cambios de incluso menor entidad, como la leve alteración del orden de ciertos poemas dentro de la secuencia de cada libro (así en Suma de varia intención y Renta antigua), o la sustitución de artículos («el ávido» donde antes «un ávido», 2000: 140; «el gato» donde antes «un gato», 2012: 51; e, 
inversamente, «un mal» en vez de «el mal», 2012:57) o la introducción y supresión de conjunciones («ni aun» en vez de «aun», 2008a: 11; «mas» en vez de "pero», 2008a: 39; «y el Héroe» en vez de «el Héroe», 2012: 55; «por» en vez de «en», 2012: 72, etc.). Como se echa de ver, no hemos parafraseado todos y cada uno de los casos recogidos en nuestro aparato crítico positivo, pero sí los principales y, sea como fuere, toda la tipología que observamos.

En conclusión, en estas páginas hemos revisado las modificaciones introducidas por Juaristi en el trasvase de revista a libro de catorce de sus poemas, así como los nuevos cambios insertos por el autor en la edición en prensa de sus poesías completas. Como se ha podido ver, los cambios nunca implican modificaciones sustanciales en la índole de los textos y casi siempre atienden a pequeños matices léxicos, métricos, y, en las raras ocasiones en que el sentido se ve afectado, se hace con miras a que los poemas resulten más accesibles. 


\section{BIBLIOGRAFÍA}

Balbín, Rafael de (1968). Sistema de rítmica castellana, Madrid, Gredos, 2. ${ }^{a}$ ed. aumentada.

Baroja, Pío (1963). Las inquietudes de Shanti Andía, Madrid, Espasa-Calpe, 1963.

Blecua, Alberto (1983). Manual de crítica textual, Madrid, Castalia.

Díaz de Castro, Francisco (2002). «La dorada morralla de la vida», en Vidas pensadas. Poetas en el fin de siglo, Sevilla, Renacimiento, pp. 116-131.

IrAVEDRA, Araceli (2014). «¿Un tema olvidado?», Ínsula. Revista de Letras y Ciencias Humanas, 811-812, pp. 2-3.

Juaristi, Jon (1969). «Dos poemas», Poesía Española, segunda época, 202 (octubre), pp. 26-27.

— (1986). «Poética», en El estado de las poesías, monográfico de Los Cuadernos del Norte, 3, Oviedo, Caja de Ahorros de Asturias, pp. 143-144.

— (1987). «Baladas del fin de la juventud», Calle Mayor. Trimestral de Literatura, Crítica y Artes, 6, pp. 89-90.

— (1989). «Deber de podredumbre», Renacimiento. Revista de Literatura, 3, p. 11.

— (1992). «Intento formular mi experiencia de la poesía civil», Renacimiento. Revista de Literatura, 7, p. 4.

— (1993a). «Comentario de texto», Revista de Occidente, 144, pp. 93-94.

_ (1993b). «Dos ciudades», Hélice. Revista de Poesía, 1, p. 33.

— (1994). Mediodía. Poesía 1985-1993, Granada, Comares.

— (1995). «Il compagno», Hélice. Revista de Poesía, 5, pp. 41-42.

— (1996a). Tiempo desapacible, Granada, Comares.

— (1996b). «Poemas», Clarín. Revista de Nueva Literatura, 6, pp. 34-35.

— (1997). «Dama de Elche», Renacimiento. Revista de Literatura, 15-16, p. 46.

— (2000). Poesía reunida (1985-1999), Madrid,Visor.

— (2002). Prosas (en verso), Madrid, Hiperión.

— (2006). Cambio de destino. Memorias, Barcelona, Seix Barral.

— (2007). «Maestros», ABC, 3/12/2007, p. 16.

—_ (2008a). Viento sobre las lóbregas colinas, Madrid,Visor. 
- (2008b). «Ligero de equipaje», «Restaurante chino», «El hombre tranquilo», "Aphasia», Renacimiento. Revista de Literatura, 61-62, pp. 3-5.

— (2010). «Tomás Bilbao Hospitalet, Ministro de la Segunda República española, desembarca en Veracruz (22 de mayo de 1942)", Renacimiento. Revista de Literatura, 65-66, pp. 86-87.

- (2012). Renta antigua, Madrid,Visor.

- (2018a). Los pequeños mundos, Pamplona, Ipso.

— (2018b). «2017», Anáfora, 15, p. 5.

- (2019). «Elcano», ABC, 8/9/2019, p. 14.

— (en prensa). Derrotero. Poesía reunida (1969-2021), Sevilla, Renacimiento.

Juaristi, Jon y María Pino (2011). A cambio del olvido. Una indagación republicana (1872-1942), Barcelona, Tusquets.

Leuci,Verónica (2016). «Jon Juaristi, el juego de hacer versos», Espéculo, 57, pp. 106-118.

— (2017). «Oficio de falsario: Jon Juaristi y la poesía autoficcional», Impossibilia, 13, pp. 85-105.

Lluch-Prats, Javier (2009). «Las variantes de autor en el proceso genético y editorial del texto literario contemporáneo», Lapurdum, 13, pp. 233-244.

LóPez-Pasarín, Alfredo (2018). «Presencia de Gil de Biedma en la poesía de Jon Juaristi», Sinoele, 17, pp. 339-348.

Marvell, Andrew (2006). Poemas, ed. y trad. de Carlos Pujol,Valencia, Pre-Textos.

Olay ValdÉs, Rodrigo (2017). «Jon Juaristi, metalingüístico y sentimental» [entrevista], Anáfora, 10, pp. 28-33.

— (2019). «Una eruditería juarístea», Anáfora, 16, pp. 29-31.

Tanganelli, Paolo (2014). «Borradores e impresos unamunianos. Variantes de autor y "de copia" en Del sentimiento trágico de la vida (con unas calas intermedias en la tradición de La Venda, cuento y drama)», Creneida. Anuario de Literaturas Hispánicas, 2, pp. 161-198. 